\title{
Clinical and magnetic resonance imaging monitoring in progressive multifocal leukoencephalopathy treated with pembrolizumab: a case report
}

\author{
Jakob Stögbauer $^{1}$ (D) $\cdot$ Walter Schulz-Schaeffer ${ }^{2} \cdot$ Ruben Mühl-Benninghaus $^{3} \cdot$ Piergiorgio Lochner $^{1}$
}

Received: 1 April 2020 / Accepted: 4 July 2020 / Published online: 22 July 2020

(C) The Author(s) 2020

Dear Dr. Federico,

The development of progressive multifocal leukoencephalopathy (PML) under immunosuppressive therapy using CD20 inhibitors such as rituximab is still a rarely observed event in everyday clinical practice and requires increased attention. Furthermore, there is still no causal and evidence-based therapy for the disease. In the recent past, several cases of successful therapy attempts using the programmed cell death 1 protein-inhibitor (PD1) pembrolizumab have been described [1].

In this report, we present the case of a 54-year-old woman who developed an infratentorial PML as a result of combined rituximab, cyclophosphamide, hydroxydaunorubicin, vincristine, and prednisolone (R-CHOP) therapy and in whom three doses of pembrolizumab showed no clinical improvement.

The patient was originally diagnosed with diffuse large cell B cell lymphoma of the non-germinal center B cell (nonGCB)-like type of the small intestine in December 2018. A combined therapy of surgical resection and intravenous chemotherapy was performed using 6 cycles of R-CHOP resulting in complete clinical remission. In November 2019, she was introduced to our clinic with a newly occurring weakness of the right hand, a speech disorder, and dizziness. A neurological examination revealed hemiataxia of the right side of the body. Laboratory tests (including inflammatory indices)

Jakob Stögbauer

Jakob.stoegbauer@web.de

1 Department of Neurology, Saarland University, D-66421 Homburg, Saarland, Germany

2 Department of Neuropathology, Saarland University, D-66421 Homburg, Saarland, Germany

3 Department of Neuroradiology, Saarland University, D-66421 Homburg, Saarland, Germany were unremarkable. A cerebral magnetic resonance imaging (cMRI) showed a lesion in the area of the right cerebellar hemisphere resembling an edema, without contrast enhancement (Fig. 1, at admission). The secondary involvement of the CNS by DLBCL was excluded because no evidence of clonal B cell population in flow cytometry of the sample of the lumbar puncture was found. Furthermore, cMRI showed neither diffusion restriction nor contrast enhancement which would contribute to the diagnosis of CNS Lymphoma. The microbiological findings were unremarkable. The virological analysis revealed John Cunningham virus (JCV) in the aspirate finally leading to the diagnosis of PML.

Afterwards, we initiated an individual healing attempt with an off-label therapy using mirtazapine with daily target dose of $45 \mathrm{mg}$ (three times/day) and cidofovir infusions. A cMRI revaluation (Fig. 1, 15 days) showed a clear extension of the PML lesion. A second lumbar puncture showed an inflammatory process with a lymphocytic pleocytosis and a high content of cytotoxic T-cells. Consistent with these findings, a florid infection with an increase in the JC viral load by more than two log levels to 3,500,000 copies/ml was determined by quantitative PCR (Fig. 2). In order to restore the immune function, we further escalated the therapy adding the PD1 inhibitor pembrolizumab with the aim of activating JC virusspecific T cells using the same scheme Cortese et al. described ( $2 \mathrm{mg} / \mathrm{kg}$ of body weight, every 4 weeks; altogether three infusions) [1]. Unfortunately, the symptoms of the patient worsened with increasing neurogenic dysphagia, a progressive dysmetria and paresis of the right side in spite of a second infusion of pembrolizumab. A follow-up MRI revealed a further progression of the defect areas including bilateral parts of the brain stem (Fig. 1, 40 days). Despite our efforts, the patient's condition continued to deteriorate even after the third administration of pembrolizumab. The patient underwent meanwhile a tracheostoma and a percutaneous endoscopic gastrostomy. The last cMRI showed again a progression of 

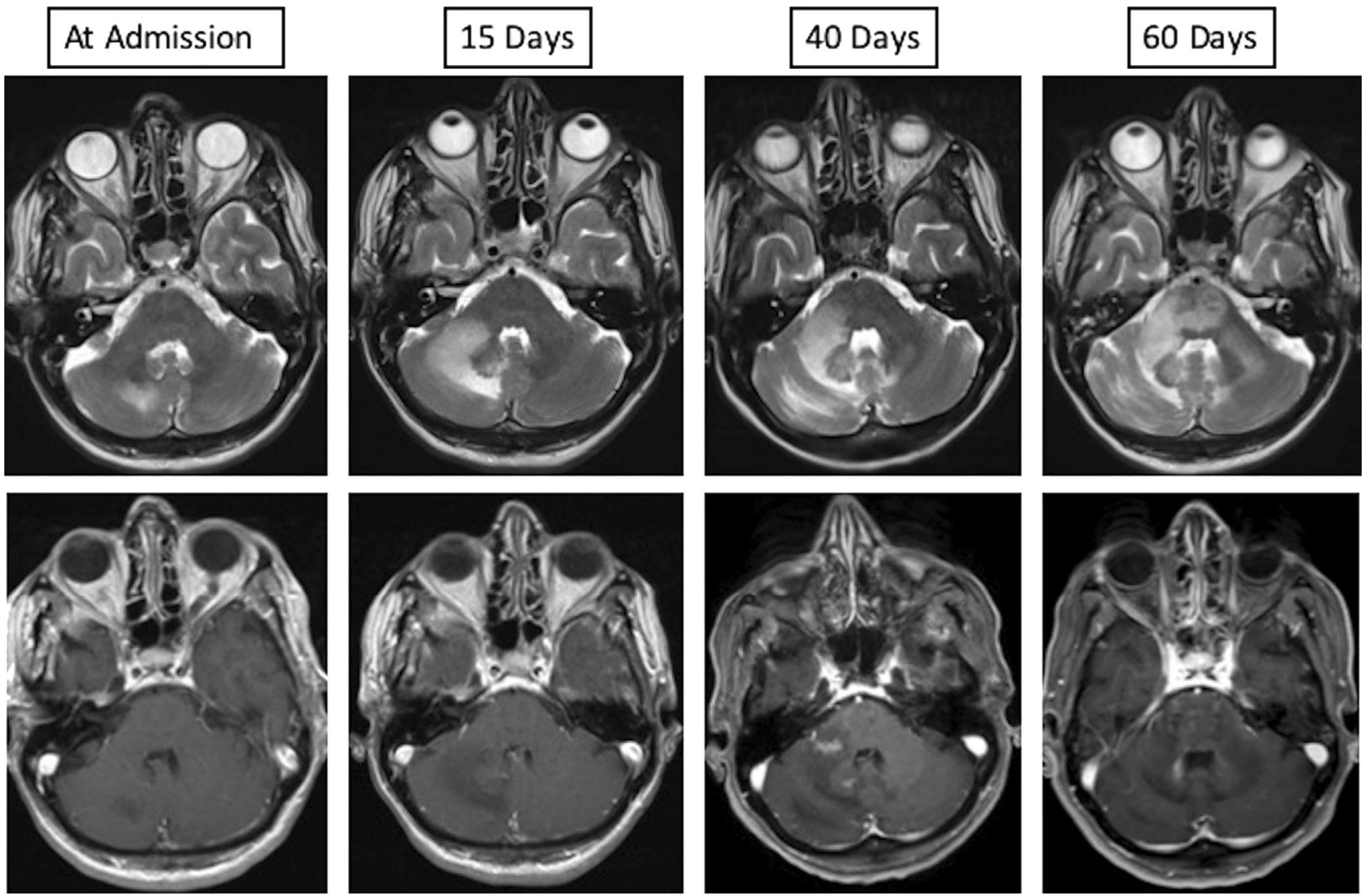

Fig. 1 Cerebral magnetic resonance imaging (cMRI) findings. Upper row shows progressive hyperintensity of the infratentorial white matter on axial T2 images representing increase of parenchymal edema (left to right images). Lower row shows axial $\mathrm{T} 1$ contrast-enhanced images of the first

enhancement of the infratentorial white matter at day 40 after initial imaging that represents the switch from progressive multifocal leukoencephalopathy (PML) to PML immune reconstitution inflammatory syndrome (IRIS) as a radiological finding

the PML lesions with patchy contrast enhancement suggestive of immune reconstitution inflammatory syndrome (IRIS) (Fig. 1, 60 days). Clinically, apart from anarthria, dysphagia, and tetraparesis, the patient had a nearly complete horizontal as well as vertical ophthalmoparesis. Due to the pronounced clinical deterioration, palliative therapy was initiated under which the patient died within 10 days.

For a long time, PML has been observed almost exclusively as a rare opportunistic infection in the context of Acquired Immune Deficiency Syndrome (AIDS) [2]. Parallel to the
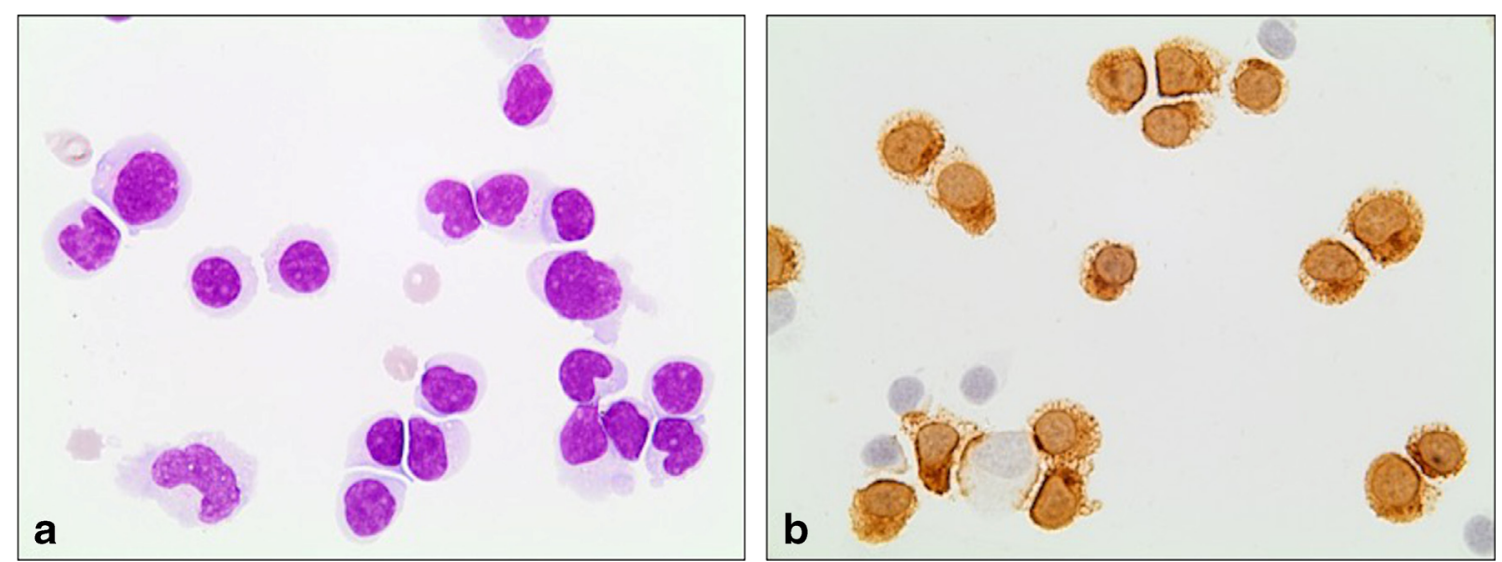

Fig. 2 Microscopic images of cerebrospinal fluid cells. a Lymphocytic pleocytosis and cell activation, May-Grünwald Giemsa stain. b Note the high amount of cytotoxic T-Zells (approx. 70\%, CD8-immunoreaction in brown (magnification $\times 100$ ) 
increasing clinical use of monoclonal antibodies in the therapy of malignancies and autoimmune diseases such as multiple sclerosis, the incidence of PML has visibly risen. While the risk is well known when patients are treated with the integrin $\alpha 4$ inhibitor natalizumab (Tysabri ${ }^{\circledR}$ ) wherefore a routine check of the JC virus status is carried out prior to administration, many people are unaware of the existing potential of a PML manifestation when patients are treated with the CD20 antibody rituximab. The PML is still considered as a very rare side effect of rituximab therapy and occurs in less than 1:10,000 patient cases, although several studies report a significantly higher incidence [3]. Cases similar to this one show that the possibility of PML in patients affected by nonHodgkin-lymphoma and treated with monoclonal antibodies should be considered in the context of an appropriate clinical syndrome. A prophylactic review of JC serostatus prior to therapy with CD20 inhibitors remains to be discussed. There is still no evidence-based curative therapy for PML and the existing recommendations are usually derived from individual case studies. The most common therapeutic approach is a direct therapy approach using the antiviral drug cidofovir in combination with the tetracyclic antidepressant mirtazapine. Recently the possibility of immunization using a JCV capsid protein (VP1) in combination with interleukin 7 and imiquimod (a toll-like receptor 7 agonist) has also been described in isolated cases [4]. However, so far, this treatment option is not suitable for patients who developed PML as a result of therapy with a monoclonal antibody and are therefore unable to achieve immediate immune reconstitution. In 2019, Cortese et al. discussed an alternative, immunomodulatory treatment option using the PD1 inhibitor pembrolizumab, so far approved for the therapy of several advanced tumor diseases [1]. The new approach pursues the activation of JC virus-specific CD4+ $\mathrm{T}$ cells in order to reinvigorate anti-JC virus immune activity. The study included a group of eight patients with PML, five of whom were clinically stabilized or even benefited under pembrolizumab. Subsequently, further therapy trials with the PD1 inhibitor were described, which paint a mixed picture $[5,6]$. Some case reports draw a positive picture, in others, as in the present case, no positive effect on the course of the disease could be shown.

At this point in time, no indicator of a patient's response to therapy could be shown, but a clinical arrest of the disease was observed in some patients treated with PD1 inhibitors. Neither the initial JC viral load in the $\mathrm{CSF}$, nor the time interval between diagnosis and first administration, nor the patient's age seems to be a reliable prognostic factor [5].

In conclusion, more patients treated with PD1 inhibitors are warranted to prove if and in which stage of the disease PD1 inhibitors should be administered in therapy of patient with PML.
Acknowledgements Open Access funding provided by Projekt DEAL.

Data availability Not applicable.

\section{Compliance with ethical standards}

Conflict of interests The authors declare that they have no conflict of interest.

Ethical approval For this type of report, formal consent is not required. This article does not contain any studies with animals performed by any of the authors.

Code availability Not applicable.

Open Access This article is licensed under a Creative Commons Attribution 4.0 International License, which permits use, sharing, adaptation, distribution and reproduction in any medium or format, as long as you give appropriate credit to the original author(s) and the source, provide a link to the Creative Commons licence, and indicate if changes were made. The images or other third party material in this article are included in the article's Creative Commons licence, unless indicated otherwise in a credit line to the material. If material is not included in the article's Creative Commons licence and your intended use is not permitted by statutory regulation or exceeds the permitted use, you will need to obtain permission directly from the copyright holder. To view a copy of this licence, visit http://creativecommons.org/licenses/by/4.0/.

\section{References}

1. Cortese I, Muranski P, Enose-Akahata Y, Ha S-K, Smith B, Monaco M, Ryschkewitz C, Major EO, Ohayon J, Schindler MK, Beck E, Reoma LB, Jacobson S, Reich DS, Nath A (2019) Pembrolizumab treatment for progressive multifocal leukoencephalopathy. N Engl J Med 380:1597-1605

2. Romano L, Capiluppi E, Macerollo A, Cislaghi G (2019) An unusual case of PML in HIV patient presenting with diplopia. Neurol Sci 40(5):1081-1082. https://doi.org/10.1007/s10072-018-3665-y

3. Focosi D, Tuccori M, Maggi F (2019) Progressive multifocal leukoencephalopathy and anti-CD20 monoclonal antibodies: what do we know after 20 years of rituximab. Rev Med Virol 29:e2077

4. Sospreda M, Schippling S, Yousef S, Jelcic I, Bofill-Mas S, Planas R, Stellman J-P, Demina V, Cinque P, Garcea R, Croughs T, Girones R, Martin R (2014) Treating progressive multifocal leukoencephalopathy with interleukin 7 and vaccination with JC virus capsid protein VP1. Clin Infect Dis 59:1588-1592

5. Du Pasquier RA (2019) Pembrolizumab as a treatment for PML? Waiting for Godot. Neurol Neuroimmunol Neuroinflamm 6:e629

6. Rauer S, Marks R, Urbach H, Warnatz K, Nath A, Holland S, Weiller C, Grimbacher B (2019) Treatment of progressive multifocal leukoencephalopathy with pembrolizumab. N Engl J Med 380: $1676-1677$

Publisher's note Springer Nature remains neutral with regard to jurisdictional claims in published maps and institutional affiliations. 